\title{
A code of ethics proposal for Palestinians' educators: attitudes and themes
}

\author{
Sahar Shweiki ${ }^{1}$ Aysha Abd-Rabo ${ }^{1}$ - Amjad Badah ${ }^{2} \cdot$ Safia Tarteer $^{1}$. \\ Samira Mahmoud ${ }^{1}$. Ahmad Odeh ${ }^{1}$. Saida Affouneh ${ }^{3}$
}

Accepted: 19 July 2021 / Published online: 7 September 2021

(c) The Author(s), under exclusive licence to Springer Nature Switzerland AG 2021

\begin{abstract}
The ethical aspect of the online learning is a major priority that has to be addressed by all stakeholders in the educational field. This study sheds the light on establishing a code of ethics for the online learning based on a Palestinian vision. A content analysis was used for related literature in order to drive themes and major topics, then a qualitative approach was used to collect data to test the themes from the field. The study population consisted of 21 educators who have previous experience in online learning and 4 key university specialists with pedagogical experience. Interviews and focused group meetings were conducted with participants. The findings revealed that most of educators' attitudes toward establishing a code for ethics in online learning mode are positive. The study also revealed that all educational stakeholders play a vital role in the success of online learning and particularly in practicing positive ethics.
\end{abstract}

Keywords Ethics $\cdot$ Code of ethics $\cdot$ Online learning $\cdot$ Educators

\section{Introduction}

No one can refute the importance of technology in our life (Soro et al. 2019). This importance has increased during the emergence of COVID-19 pandemic, which caused unprecedented disruptions to many life sectors. Education is one of the main sectors that have been dramatically affected. Schools and universities closures caused by the pandemic have forced these institutions to find alternative solutions to continue the educational process. The shift to online learning manifests such change (Aung and Khaing 2015). According to Aggarwal et al. (2020), the adoption of online learning has spread like wildfire all over the world nowadays, affording

Amjad Badah

amjad.badah@hotmail.com

Extended author information available on the last page of the article 
powerful instruments to dynamic educational environments including content, student-teacher interaction, feedback, assessment and evaluation.

The development of technology and assessment systems have taken headway solutions for education to continue the learning process and to reduce the gap that raised during the lockdown (Vitoria et al. 2018). However, this led to some challenges in all aspects of education especially the ethical dimension (Aggarwal et al. 2020). These challenges vary from one place to another due to culture, readiness and content. Thus, online learning is more likely to face ethical challenges than the traditional education. Ethics is what people should do, it is concerned with moral values, ethics and justice (Schultz 2005:1). The principle which judges online learning environment is obeying rules. Khan (2005) classified ethical considerations in online learning as social and political influence, cultural diversity, bias, geographical diversity, student diversity, digital divide, etiquette, legal issues(Khan 2005 as cited in Toprak et al. 2010).

With the emergence of COVID-19, Palestine has been one of the countries that shifted towards the online learning paradigm, where it has become a requirement rather than luxury to overcome educational institutions closures. Given such transfer, a need to govern the online learning process from an ethical view has emerged. Different ethical considerations including academic dishonesty have to be considered when it comes to online learning. To this end, a Code of Ethics needs to be established so that the educational outcomes are well-protected.

There is a general assumption that a code of ethics has a positive and great impact on the behavior of the student, (Kusumaningrum et al. 2019). The code of ethics focuses on the need to protect the public from harm. Moreover, the code of ethics has many goals. It first enhances morals among members of profession by formulating a number of ethical standards. Besides, it obtains the community confidence and promotes community trust and in the teaching profession (Ontario College Teachers 2006). Moreover, it enhances the relationship between the teachers and their colleagues as well as students and other people who interact with them from time to time (Farahani 2012).

According to Abbott et al (2000) there are some unacceptable practices that appeared in an online learning environment like cheating. In fact, recent studies reported that academic dishonesty is rising up. In this regards, Berglund et al. (2015) reported that $80 \%$ of the American High school students admitted to cheat in exams. Many reasons lead to academic fraud in online learning including a motivation for cheating, pressure, anxiety, lack of knowledge related to academic regulation and personality (Brown 2008).

Accordingly, ethics have become vital in online learning education. According to Muhammad et al. (2016) ethics is moral behavior. Among the bjectives of the educational institution is to develop the students' values. The purpose of education is to give a path for a successful life. Ethics issues have become more dominant due to the use of technology. UN and its specialized agency UNESCO started special "Ethics Teaching Training Courses (ETTC) program". During the technology integration, educational institutions are facing ethical issues, where students have become more averse to ethics. It is faced by educational institution use of technology and internet (Aung and Khaing 2015). In the U.S.A, for example, 59\% of all students 
enrolled in online learning programs have admitted that they have been in some kind of academic cheating in their academic period. Using mobile phone also has made students adopt unethical conducts. Unethical use of ICT has promoted plagiarism in academic institutions, (Muhammad et al. 2016).

Developing a suitable code of ethics will hopefully, if not prevent, reduce this fraudulence in online environment. The current study attempts to suggest a suitable, interactive and efficient code of ethics for e- learning environment to increase the awareness of values, responsibilities of teaching as well as to improve the practice of all stakeholders.

Wales, Scotland, Ireland, Australia, South Australia, Pakistan and the USA, to mention just a few, have moved to online learning mode during the COVID-19 pandemic. However, some challenges have emerged. Ethics related issues are one of the most dominant aspects of such challenge. Discussing the ethical issues and articulating ethical standards to organize the relationship between all parties of the learning process are important aspects in online learning. Scotland has put down some guidelines for teacher's education courses. Similarly, each state in the USA, has its own teaching license (Popovici and Mironov 2015). In England and Wales teachers a training agency was established for "initial" teachers to train them on the steps of education reform. The established General Teaching Council for England helps to put professional attributes on the agenda of teacher's training. They developed a code of values and educational practice. They believed that during the challenges, which face learning process, it is important to develop teaching values and morals to organize the learning process. Without such values, teaching becomes a mechanical skill. As a matter of fact, values are the main part of the learning process as it shows how teachers teach and why (Aggarwal et al., 2020). The aim of Education Reform in those countries is to promote the values, morals, and the social education of their pupils. Morality is about rules which lead our actions (Aung and Khaing 2015).

\section{Statement of the problem}

With the growing tendency towards online learning education worldwide and the emergence of COVID-19, it has become vital to have an ethical code that can guide this mode of education effectively. Being one of those countries that have gradually shifted to online learning at schools and university levels, Palestine is in high need for such code. In fact, no local attempts were undertaken to establish a code for online learning due to many factors. First, there have been no high graduate programs that are highly specialized in learning. The first program, which is one of its kinds in the Palestinian universities, was launched in the 2019 at one of these universities. This program offers a $\mathrm{PhD}$ in learning and teaching, where one of its courses revolves around the ethics and standards of teaching profession. Thus, the ethical aspects of education particularly online learning have been well-examined since then. Second, traditional education, where the issue of ethics is less demanding, used to be favored over the digital, as it were, one. Therefore, the development of a code for ethics has been a demanding need more than before. Consequently, the 
purpose of the present study is to develop a code of ethics for the online learning education mode that suits the Palestinian context.

\section{The purpose of this study}

Given the possibility of unethical conducts increase in the online learning environment, this study aims at developing a proposed code of ethics, which suits this type of education in Palestine. Such a code would clearly organize the relationship between all the stakeholders of the educational process including teachers, students, and the institutional organization, parents, supervisors and instructional designers. Other domains of the educational system such as the surrounding environment, teacher assessment, online learning resources and community are included, too. To develop a code of ethics for the online learning education in Palestine, the present study addresses the following two questions:

1. What are the attitudes of Palestinian educators toward building a code of ethics for online learning?

2. What are the proposed codes of ethics for online learning context?

\section{Methodology}

The researchers used qualitative approach in order to answer the research questions. To develop a suitable code of ethics, the researchers adopted a collaborative approach where more than one tool is used.

\section{Participants}

The population of this study consisted of 21 educators who have experienced online learning before. It also included 4 specialized key people with long pedagogical experience background from the Palestinian universities and schools. The first draft of the proposal was discussed with 8 educators and 2 key people in the form of a focused group via Zoom application to benefit from their opinions to modify accordingly. The participants are school teachers, school headmasters, supervisors, and university instructors with varied teaching experience. Some of them work in West Bank mainly Nablus \& Ramallah. Others, however, work in Jerusalem districts. Their major include Arabic language, English Language, Technology and Mathmatics.

\section{Procedure}

The study took place from May-July 2020 and its procedures mainly consisted of the below seven stages. 


\section{Stage 1: environmental scan and background}

In its broad sense, culture can be defined as the accumulative values, norms and beliefs shared by a certain community. When it comes to the learning environment, culture plays a vital role in affecting both learning and teaching processes. It affects the way of learning where teachers need to take some principles in consideration including universal learning ones, cultural differences and individual learning style. According to Khan (2005), the features of contexts have to be taken into consideration while designing learning environment. In the present study, the respondents have recommended several thoughts on the learning environment.

The researchers revised the development history of the previous codes of ethics in different countries such as Australia, South Australia, Wales, Scotland, the USA, and the UK to follow the development of morality in theses countries. All these countries agreed to reform education and organize the relationship between teachers, students, parents, and society. It is believed that there must be a code of ethics that would control the relationship between all stakeholders. Without ethics, values and morality, the learning process becomes a mechanical one (Khan 2005). In fact, cross-cultural communication and asking different questions from different cultural and different demographic areas is a challenge.

\section{Stage 2: reviewing previous codes of ethics}

The researchers revised related previous literature and some codes of ethics around the world to integrate them to study data. Code of ethics in Wales, Scotland, Ireland, Australia, South Australia, Pakistan and the USA as well as UNECEF criteria were specifically revised and further analyzed. Morality is about rules, which leads teacher's actions. General Teaching Council for England published a Code of Professional Values and Practices that helped organize the relationship between young people as pupils, teaching colleagues, other professional,the school content,learning and development,teachers obligation, teacher virtues, values and teaching, values in classroom, classroom climate, empowering students, parents and pupils, inspections, professional relationship with colleges, professional relationship in teacher education and training (Toprak et al. 2007).

\section{Stage 3: interviews}

The researchers interviewed 21 educators who utilized online learning during the lockdown of COVID- 19. The goal was to benefit from their feedback in developing a new code of ethics for online learning education. Interviews, whether done with one person or more, are suitable to elicit single and direct information from the participants in qualitative research (Maxwell 2013). The interviewees were asked about their experience concerning managing their relationship with students and their opinion towards a code of ethics in online context. 


\section{Stage 4: drafting the code of ethics}

After revising the literature, analyzing the documents and conducting the interviews, the researchers drafted a code of ethics. The researchers mainly followed the thematic analysis approach, where the participants' answers were classified into 6 themes to determine the domains of the code of ethics. They triangulated the answers and established a suitable code of ethics based on the results of the tools (Maxwell 2013).

\section{Stage 5: validation}

After the researchers analyzed the documents of ethics, they showed them to 4 ICT specialists to check their validity. The specialists are from An-Najah National University and Al-Quds Open University. Their feedback was taken into consideration for code development purposes.

\section{Stage 6: ongoing format and capacity building for implementing online learning ethics}

The researchers developed the code of ethics for all stakeholders to be adopted for online learning education.

\section{Stage 7: focus group}

The researchers conducted a focused group interview with 8 teachers and the 2 ICT specialists to benefit from their opinions in developing the final version of code of conduct proposal.

\section{Measures}

The study consisted of three main tools. The first one included revising related literature and codes of ethics from Wales, Scotland, Ireland, Australia, South Australia, Pakistan, the USA as well as UNECEF criteria. The second tool included interviews with twenty-one Palestinian educators from different directorates, of which are two ICT specialists. The third tool was focus group meeting some teachers and experts benefit from their view in modifying and developing the code of ethics that the researchers established.

\section{Data analysis}

The data collected from the above-mentioned tools were analyzed qualitatively through adopting the thematic analysis approach to build the overall themes in this study. By doing so, the questions of the study are answered. 
In fact, "Theme" is the main product of data analysis that yields practical results in the field of study (Krauss 2005). The researchers used the thematic analysis, which is considered a qualitative analysis used for identifying, analyzing, and reporting patterns (themes) within data. Moreover, it often interprets various aspects of the research topic (Boyatzis 1998).

\section{Results}

The data collection methods highly supported the researchers to answer the research questions as shown in this section.

\section{Results of the first questions}

\section{What are the attitudes of Palestinian educators toward building a code of ethics for online learning?}

It can be argued that the qualitative analysis of the data showed positive attitude towards the importance of building a code of ethics that organizes online learning. (R) said "building a code of ethics is a supporting step to enhance online learning, because it protects both teachers and students from the disadvantages of online learning". An administrator said: "code of ethics controls all of us and we can take it as a legal document to report corruption by any stakeholder". (A) expressed his view on establishing a code of ethics saying that "it is a must especially in the time of Corona. We all are obliged to teach via internet". Similarly, (S) said, "The code of ethics preserves the rights of each the teacher as well as the students, thus it must be distributed to all schools and teachers". Furthermore, many of the respondents requested to ensure that every stakeholder should receive a copy of the code and become aware of all its items.

The educators emphasized the importance of monitoring the online learning process. Z/ a male teacher said, "the codes of ethics shall have the authority to determine what is acceptable and what is not in virtual classes". Likewise, (A) told "building a document would allow the person to know his limits in practicing or using electronic tools in education. "The document would constitute a deterrent to both the teacher and the student", she added. (M) said, "the code is a prerequisite that protects all participants in the educational process; teachers, students, schools and the educational community as a whole. She added, "it is an administrative tool, and a vital reference in the time of corona virus and the following stages since online learning became a must to enhance the educational process.

It is worth mentioning that three respondents disagreed with the idea of establishing code of ethics for the online learning mode because they doubt its impact to control the behavior. One teacher sighed and stated " It is a waste of time, no one would 
adhere to the codes". Similarly, another respondent added "Are you sure that students will be afraid to cheat or misbehave if you tell them about the code of ethics?" On the other hand, a third teacher argued that "I think our ethics and religion are supposed to control our actions, if not, millions of codes won't be able to do this."

Moreover, some participants have negative attitude towards setting a code of ethics, because it restricts freedoms, (Q) said, "In general, this code may limit freedoms". In addition, some believe that this code may have political or racist covered aims, (Q) stressed that the code should not be used for personal or political purposes. He stated, "People who have authority, can use the code for personal or political purposes to exclude some people's thought or effort. To manage this problem, he stressed that the controlling laws must be subject to international standards. "These standards must be governed by international standards, whether it is UNESCO for the Arab region or for (ISD) for the world organizations or the World Teachers Association."

\section{Results of the second question}

\section{What are the proposed codes of ethics for online learning context?}

According to the collected data, the researchers categorized the respondents' answers into five themes. In general, most of themes focus on both teachers and students' responsibilities and roles in online learning in addition to all stakeholders in the educational process. The themes are as follows; Teachers' Professional Responsibility, Teachers' Responsibility towards Students, The Responsibility of School Community, The Responsibility of all stakeholders towards Ethical Use of Technology and Technological Tools, and finally, The Responsibility of all stakeholders to Clarify the Risks and Limitations of Online learning.

\section{Teachers' professional responsibility}

Nowadays, teachers need to be familiar with twenty-first century skills. Among these skills is technology which constitutes a major pillar in the newly existed digital environment. This main theme revolves around acquiring teachers with high professional skills including innovative technologies that they should be acquainted with. (Z) a teacher said "teachers shall obtain the highest standards of practice by which they can continuously improve their professional competence".

With regard to readiness, a number of participants focused on the importance of having the online learning requirements available and fully prepared. In this regards, (R) a teacher explained, "We must ensure that the network and the devices are fully prepared and have alternative plans in case of any emergency such as electricity power cut or internet interruptions." She added, "we must also take into consideration to provide students with free accessible programs by smart phones especially if they don't have laptops." She added "all students have the right to get access to resources, taking into consideration students' different abilities and intelligences". In addition, M (a supervisor) added, "The content must be basically chosen based 
on what is most important for the student' needs, and what is less important must be excluded." Likewise, teachers must not be biased to their opinion. (A) a teacher stated "free debate must be prevailed and the teacher must not be bias to a specific opinion."

One of the participants emphasized that the content should respect the culture of the society. (Z) stated, "The content depends on the nature of the culture of the society in which I live before we follow other external cultures, however we must respect all of them ". Another female administrator pointed to the "necessity to choose content related to achieving the intended educational goals." She adds: "we shall make a content analysis for the digital content presented to students. Thus, we must choose the most important ideas and facts that we want to convey to the student and relate them to learning outcomes of their level. For example, there is some unnecessary information so I must focus on the important facts and concepts that I want the student to understand".

On the scientific level, teachers must check the truthfulness of the accessed content. M/a supervisor said "teachers must make sure that the information they present to student is correct and avoid haphazard information...this is why we emphasize using particular resources". However, responses showed contradiction between the results about the ability of designing a digital scientific content. (T) a technology teacher stated that "I can build my own instructional content considering the international criteria in terms of technical standards related to preserving privacy, and clarity of instruction, for example, the time to deliver the task must be specific, and I am keen to use the latest technological tools".

On the other hand, (A) said that "I did not choose the content! My supervisor did. The ministry did not allow us to choose. I am not satisfied with that; I wish they consulted teachers because we have direct contact with both content and students. Thus, we know better about their needs and abilities" she added "the ministry emphasized particular subjects at the expense of other ones under the corona pandemic condition". (Z) stated "teachers can produce interactive activities taking into consideration the individual differences of students, and therefore, ensuring diversity of presentation methods. Moreover, (F) a supervisor stated "The content should be selected according to students' age, educational levels, the technological infrastructure, the targets, and whether it can be displayed through online learning or not". (R) emphasized the importance of taking the individual differences into consideration when designing e-classes. She added, "the class time must be divided into three or four sections among clever, intermediate and weak students. It is crucial to take the nature of difference between subjects in accordance to students' preferences. However, (S) a school principal argued that "all of us shall adhere to the curriculum and the apps set by the ministry of education". Another supervisor confirmed this view saying "teachers shall adhere to the resources permitted by the ministry, or at least inform the supervisor of the adopted resources. As for (A), the content that presents contain political, religious or racist messages should be excluded as it leads to many problems in our Palestinian society. 


\section{Teachers' responsibility towards students}

This theme mainly includes values of respect, care, privacy and equity. Since teachers are role model to their students, they shall treat them with high manners. (A) stated "students imitate their teachers, so we must be careful when we deal with them". However, (R) said "teachers shall maintain verbal, physical, emotional and social limitations with students, yet they must respect students' rights and dignity". She added, "students shall respect their teachers as well as their colleagues". (Z) stated "the code should oblige both students and teachers to attend the class on time, otherwise any late participant will get a punishment". Y (a school principal) supported this opinion saying that "we need to respect the laws, and attendance time". (R) also addressed the attendance issue "there must be a minimum attendance level for e-classes, otherwise students will be subject to punishment... Simultaneous classes must be attended at least 80 per cent, laws are binding on all". Another female teacher (R) stated, "Commitment to time, effective presence and real participation are basic ethics in online learning".

As for the bullying phenomenon in the online learning environment, a number of participants rejected some of the behaviors that some teachers and students do towards other students. (R) stated "it is possible that teachers are joking with their students in online classes. Students may consider this action as unintended bullying; however, the teacher must be careful about that". (A) expressed that "insult, bullying and lack of mannersmust be prohibited by law".

Regarding digital equity, number of participants stressed the importance of digital equity by the teacher towards his students. (A) pointed out that "clarity in the instructional design of the electronic course will lead to digital equity. G (a teacher) stated, "There must be a clear mechanism for communicating with students. The teacher should not favor one student at the expense of another. This is considered double standards in treatment. He added, " in real classroom, it is possible to achieve social justice, but in virtual classes justice is somewhat ignored and there is a fear of misunderstanding, and as far as possible, the teacher must try his best to reduce the existing digital gap.

Communication between teachers and students on social media as well as teaching system should be clear enough. This includes limiting the time of delivering the tasks, clarifying assignments, instructional standards and scientific standards such as important data and information in the class. Such practices would help the teacher to deal equally with students.

(H) a school principal, indicated that the teacher should not prefer one student at the expense of others... every student is important; each student deserves attention and guidance." Similarly, (A) focused on the importance of allowing all students to participate in the class and indicated the sensitivity of this matter to the village students. She explained "In villages, for example, things differ from city; students may protest against choosing one student to participate not them, they clearly declare that teachers are biased to some of the village families... This applies to online learning as well, so the teacher must allow everyone to participate." 
(A) stated "we must interact clearly with students, considering their age, culture, religion, social and economic status, their educational needs. In addition, we must evaluate them fairly" She explained "the students' economic status may prohibit them from affording technical devices, or access to internet, so we either help them overcome this obstacle or never add another burden to them., They may hate us and the whole educational process".

The participants also emphasized providing equal educational opportunities for students either in presentation or in evaluation. In this regard, (Z) said "The process of digital equality is very important, especially in evaluation and scoring. The tools, means and mechanism used for scoring must be clear". One male Supervisor said 'it is compulsory for teachers to apply a variety of assessment tools. Moreover, evaluation method must be clear to achieve equity among students, both male and female, have the right to accomplish their projects." However, "students must know that cheating in electronic exams is forbidden, whoever commits cheating must be punished".

On the other hand, (M) a teacher, focused on "the need for equity in evaluating the teachers by their supervisors who shall take into account the lack of experience of some teachers in managing such virtual lessons or using some electronic programs to design exams and working papers".

All participants actually agreed on the importance of digital privacy of all stakeholders. (Z) said "The digital privacy of the teacher, the student and the instructional designer must be considered. This is a very important issue, and for the parents as well". He added "The teacher also is not allowed to share photos of his students on the internet, and this is considered private because it may harm the reputation of others".

(H) a school principal, stated, "The teacher shall keep the information that pertains to his students secret in order to preserve their privacy.... The teacher must preserve the student's privacy in terms of grades and students' academic level." A male supervisor stated "according to my opinion, privacy means not to post photos, names nor to ask the student to open the mike or the camera. (Z) said: "I, as a teacher, should not take a screenshot of this meeting and post it on social media because it is a violation of digital privacy, however, I can take attendees' permission. ( Z) emphasized, "Even if a female student turns on the camera during the class, she knows that I am going to see her. However, I have no right to take a record and post it on YouTube, for example, except with her permission because this would be a violation of the privacy of this student."

(G) referred to the privacy of parents, emphasizing that it "should not be violated, especially if a parent is forced to give their own mobiles to children for the purpose of online learning in light of the Corona pandemic." Another female teacher (R) stressed "the student must not share the data presented inside the class or give it to others outside the class. This is part of digital privacy."

(Z) ended up saying "the code of ethics must consist of two main issues; the digital privacy, which must be taken into account by the teacher, the student, the instructional designer and sometimes the parent and the digital equity, which is equal to social justice that prevails in the classroom, must be considered by teachers themselves." 


\section{The responsibility of school community}

In its broad sense, school community includes teachers, administrators, advisors, instructional designers, and parents. This theme includes enhancing positive interaction and cooperation as well as maintaining property and resources. According to the data of the interviews and the focus groups, all stakeholders need to cooperate and build stable relationships by upholding good manners, supporting new teachers, using organizational possessions appropriately and collaborating with parents. In this regard, (R) stated, "It is a must that the students respect each other and students and school principals should respect the teacher." Similarly, (Z) said "teachers should respect each other... each person knows his limits." He added, "elder teachers need our help to engage to e-class... I helped many of them...but in other places there must be a special technical support". (A) stated "at the beginning I couldn't even start a meeting using zoom, my colleague helped me and then our supervisor held a workshop to train us... I can't say I am perfect but it is better than nothing." (A) added "my colleagues and I cooperated positively during the COVID-19 period, we unified our job in a big group... so ethics made it a standard job and it succeeded due to the cooperation between me and my colleagues."

Moreover, (R) emphasized the necessity of coordination between teachers in assigning duties and tests given to students so that this does not lead to conflicts. "There must be coordination and management of assignments and tests so that students don't become stressed and teachers do not conflict with each other, she explained". On the other hand, (R) stated, "some teachers spread rumors about their colleagues as they feel jealous". She explained, "Administrators are often surrounded by hypocrites who even don't know the minimum knowledge about online learning tools and fight creative ideas".

Concerning the teacher-parent relationship, A/a female teacher stated "mutual respect between teachers and parents is a must to enhance the learning process". Likewise, (M) stated "good relations with parents helps us to create a clear vision about our students". (A) said "parents can control their children while they have e-classes, they can also prepare a suitable environment and needed devices. (M) stressed the importance of parent's role in helping their students in online learning. "The parents' role should only be to assist the student in accessing the class and not answer any homework or exam.... I think they do the work instead of their children because I know the level of my students".

(M) stressed the importance of trust in the relationship between teachers and parents. She said "The relationship must be based on mutual trust between the teacher and the students' families.... parents' role is crucial to complement the role of the school in helping their children get information and apply it in a real situations".

In short, the desired code of ethics should outline the main lines and tasks that define the role of teachers, supervisors, administrators and students in the learning process. The role of parents is also vital in supporting this process. 


\section{The responsibility of all stakeholders towards ethical use of technology and technological tools}

This theme includes many sub-themes including taking charge of utilizing and maintaining tools, access to content, scientific integrity, intellectual property, reporting cyber bullying, preserving student data and tools or platforms selection. Teachers prefer to choose specific software features. (R) stated, "we shall use special software programs that allow only presenting content but blocking download or sharing... we have the right to preserve our effort". (Z) advised teachers when using technology in teaching. He said, "We should use technology responsibly, especially for teaching purposes... it is not a matter of flexing muscles". He added, "This does not mean to ignore recent developments and trends in the use of technology. On the contrary, we have to benefit as much as we can for the sake of our students". In this regard, (A) explained her point of view saying "technology exists as a supporting tool; we are not demanded to chase new inventions. If we mastered one sufficient platform and the basic qualification, it is enough for me."

However, there was a great gap between the teachers and the supervisor's opinions about the freedom to choose suitable platforms, apps or sites. One supervisor emphasized the necessity to adhere to the ministry choices "since the ministry provides a purchased legal version of platforms and distributes it among schools to enhance the online learning process". Whereas, (R) argued "the platforms supported by the ministry are not enough, qualified teachers can benefit from more developed apps to increase the motivation and creativity of both teachers and students". She added, "the simplest is the best... what we must emphasize is the extent that an app would reach our students, since there are apps that need stronger internet provider, so they don't benefit our students who have weak internet connection".

As for scientific integrity, three of the participants focused on the importance of commitment to honesty and truthfulness, and that these two qualities are among the most important factors for the success of the online learning process. (A) mentioned, "Honesty is a must...when the class starts it is unacceptable for me to open Zoom and go to do our chores. (M) emphasized the scientific integrity in transmitting information. He mentioned, "the process must be characterized by scientific integrity in transmitting information. I mean, the standard of ethics is integrity in receiving and transmitting information." Likewise, $(\mathrm{F})$ emphasized the necessity to find a way to prevent cheating. She stated, "we must ensure that students don't cheat, and deterrence laws must be put in place. On the other hand, (B) emphasized the importance of self-censorship for the student, especially during exams. She explained, "according to my view there must be self-censorship stemming from morals and religion because students have many tools to cheat in distance learning, and that cannot be controlled. Moreover, most participants emphasized the importance of the teacher's commitment to integrity due to its great significance in the online learning process. (R) stated "The teacher must have commitment to the importance of teaching; this is due to the teacher's conscience and integrity in transmitting the mission of education faithfully."

Moreover, teachers must decide what content is suitable to our culture and beliefs and what is not. (R) said, "We have to check information before we present 
it to our students...they may include prohibited morals such as religious or cultural encroaches". She added "I myself searched one of the most popular websites and noticed homosexual indications, so I decided not to use it".

As for intellectual property, the participants discussed the importance of preserving intellectual property rights when using educational resources. They indicated that there is a major violation by students, teachers, and even instructional designers. (Z) said, "Preserving intellectual property is very noteworthy. As a student, I am supposed to preserve ethics regarding the rights of others. For example, stealing another people's work and attributing it to me is not permissible, and this applies to the teacher, too. I mean, the teacher is not allowed to use free photos without having permission...Unfortunately, this exists and it applies to the instructional designer who designs digital content. Moreover, many teachers and even students always use ready videos and use themas they were their own materials. The question that arises is whether you as a teacher, a student or an instructional designertook a permission from the original owner of this video or image to use.

All of participants recommended that teachers shuld have a permission to apply any app during the virtual classrooms either from the ministry of education or at least from the school administration., Moreover, they emphasized respecting intellectual property of any content, and equal access to any source by all students. One of the participants (A) stressed the need for deterrent laws to curb plagiarism; "this code protects the right of original owners of YouTube video taken and used by teachers." Similarly, $(\mathrm{R})$ emphasized the importance of attributing any effort to its owner; "Credibility means every one shall refer to the original owner of any piece of content." (N) emphasized this idea saying "The educational content should be preserved for its producer, and no one must steal and attribute it to himself/herself.

Some participants considered maintaining the devices such as computers and WIFI cables and routers an important ethical issue $(Z)$ stated, "we require teachers and students to take care of the devices. Giving a lesson does not mean destroying the device or the WIFI equipment."

\section{The responsibility of all stakeholders to clarify the risks and limitations of online learning}

The data showed that female teachers are afraid of using technological tools in education because of customs, traditions and cultural factors prevailing in the society. For $(\mathrm{S})$ teacher "screenshots must be forbidden especially if the students are girls which may evoke many social concerns. Our culture and religion respect women", she added. Likewise, (A) who is a female teacher raised her concern about this saying "most parents refuse to post their daughters' photos or videos on the school websites or platforms". (N) (who) said "you have the right to say I don't agree to connect to video, because this is my personal choice... Moreover, some females refuse to participate in video conferences... we must respect the privacy of all participants".

Moreover, the participants stressed the need for educating all stakeholders of their roles and duties. (Z), for example, mentioned, "We must define the role of the teacher, the student, and the designer in the online learning environment. He added, 
"most importantly, the first or two hours at the beginning of each course or semester should be devoted to educate students about ethics of online learning. Teachers should be aware of the ethics as well. They, for example, can watch short videos on the ethics of online learning.. The Ministry and the directorate are working on passing information through various means to the teachers that shows them the acceptable ethics of online learning". (R) added "If the student is not aware of the ethic rules, then this will lead to violating morals". (A) said, "We must, for example, have laws that deter misbehaving in communicating with the teacher or university instructors. It is also necessary that there be censorship in the comments during any class; any violation will be penalized."

Moreover, penalties are justified if you encroach people's cultures, freedoms, or opinions." (Z) mentioned that the document is a deterrent law that control behavior. In general, the code is a basic document that consists of set of standards, rules or laws that must carry out the process of modifying behavior". One of the respondents (R) indicated that teachers should pay attention to the source from which the educational content is derived. These sites may contradict with the prevailing community values. She stated "It is forbidden to use platforms that broadcast morals that are not acceptable to us as Arabs and Muslims, such as Khan Academy, which supports homosexuality, and we may also have inappropriate sites for us, so we must examine the content before we present it to students and take into account their age and abilities."

\section{Conclusion}

The tremendous development of ICT and the rapid spread of the Internet in various applications have contributed significantly to the rapid multiplication of human knowledge, particularly scientific and technological ones. This has allowed the development of the educational process and the introduction of several new concepts, such as distance learning, virtual university, online learning, e-school, digital library and many others. This has prompted a growing interest in the use of online learning in schools, universities in order to provide quality and quality programmers and courses. The existence of code of ethics in online learning is a very important issue for any academic course or program. It is actually a prerequisite for the success of the educational process.

The online learning experience is considered a relatively new one for the Palestinians, so there is a great need to ensure its effectiveness by developing a code of ethics that could support to achieve this efficiency. Having a code for ethics for the online learning education in Palestine is what the present study tried to achieve. It mainly relied on the feedback gained from teachers, supervisors and university lecturers to establish such code.

The educational institutions are encouraged to consider the ethical aspects of the learning process even before the start of the online learning course. Technical training for students for connecting to cyber discussions board and online rooms is a requirement of the current era. An attention must be given concerning unethical behavior of teachers and students alike in the online learning environment. 


\section{References}

Abbott L, H. Siskovic, V. Nogues, and J.G. Williams. 2000. Learner assessment in multimedia instruction: Considerations for the instructional designer.

Aggarwal A, P. Comyn P, and P.M. Fonseca. Discussion. 2020. Continuing online learning and skills development in times of the COVID-19 crisis. 27 March-17 April. Available online: https:// www.skillsforemployment.org/KSP/en/

Aung T.N, and S.S. Khaing. 2015, August. Challenges of implementing e-learning in developing countries: A review. International Conference on Genetic and Evolutionary Computing, 405411. Cham: Springer.

Berglund A, K. Leander, K. Modig, M. Stenbeck, and L. Alfredsson. 2015, October. Online learning in an epidemiology curriculum. World conference on e-learning in corporate, government, healthcare, and higher education, (272-277). Association for the Advancement of Computing in Education (AACE).

Boyatzis R.E. 1998. Transforming qualitative information: Thematic analysis and code development. Sage Publications, Inc.

Brown T. 2008. Ethics in e-learning. Workshop for Net Business Ethics. http://www.gsim.aoyama.ac. jp/ORC/iBiZ2008/papers/Brown.pdf

Farahani, M.F. 2012. Ethics principles in distance education. Procedia-Social and Behavioral Sciences 46: 890-894.

Khan, B.H., ed. 2005. Managing e-learning: Design, delivery, implementation, and evaluation. Hershey, PA: Information Science Publishing.

Krauss, S.E. 2005. Research paradigms and meaning making: A primer. The Qualitative Report 10 (4): 758-770.

Kusumaningrum, D.E., R.B. Sumarsono, and I. Gunawan. 2019. Professional ethics and teacher teaching performance: Measurement of teacher empowerment with a soft system methodology approach. International Journal of Innovation, Creativity and Change 5 (4): 611-624.

AbdulHafeez Muhammad, Mohd. Feham MD. Ghalib, Farooq Ahmad, Quadri N. Naveed and Asadullah Shah. 2016. A study to investigate state of ethical development in e-learning. International Journal of Advanced Computer Science and Applications, 7(4). https://doi.org/10.14569/ IJACSA.2016.070436

Ontario College of Teachers. 2006. Ethical and practice standards. Retrieved September 22, 2008, from www.oct.ca/standards/?lang=en-CA

Popovici, A., and C. Mironov. 2015. Students' perception on using eLearning technologies. ProcediaSocial and Behavioral Sciences 180: 1514-1519.

Schultz R.A (ed.). (2005). Contemporary issues in ethics and information technology. IGI Global.

Soro F, I. Drago, M. Trevisan, M. Mellia, J. Ceron, and J.J. Santanna. (2019, July). Are darknets all the same? On darknet visibility for security monitoring. 2019 IEEE International Symposium on Local and Metropolitan Area Networks (LANMAN), 1-6. IEEE.

Toprak, E., B. Ozkanal, S. Aydin, and S. Kaya. 2010. Ethics in e-learning. Turkish Online Journal of Educational Technology-TOJET 9 (2): 78-86.

Toprak E, B. Ozkanal, S. Kaya and S. Aydin. 2007. What do learners and instructors of online learning environments think about ethics in e-learning? A case study from Anadolu University. In European Association of Distance Teaching Universities Conference.

Vitoria L, N. Mislinawati and N. Nurmasyitah. 2018. Students' perceptions on the implementation of e-learning: Helpful or unhelpful. Journal of Physics 1088, 012058.

Maxwell J.A. 2013. Qualitative research design: an interactive approach. Thousand Oaks, CA: Sage

Publisher's Note Springer Nature remains neutral with regard to jurisdictional claims in published maps and institutional affiliations. 


\section{Authors and Affiliations}

\section{Sahar Shweiki ${ }^{1}$. Aysha Abd-Rabo ${ }^{1}$ - Amjad Badah ${ }^{2}$. Safia Tarteer ${ }^{1}$.} Samira Mahmoud ${ }^{1}$. Ahmad Odeh ${ }^{1}$. Saida Affouneh ${ }^{3}$

Sahar Shweiki

sahar.shweiki@stu.najah.edu

Aysha Abd-Rabo

ayshe.abdrabo@stu.najah.edu

Safia Tarteer

safia.tarteer@stu.najah.edu

Samira Mahmoud

Samira.mahmoud@stu.najah.edu

Ahmad Odeh

Ahmad.odeh@najah.edu

Saida Affouneh

s.affouneh@najah.edu

1 Teaching and Learning Program, An Najah National University, Nablus, Palestine

2 Applied Linguistics \& Translation, An Najah National University, Nablus, Palestine

3 Faculty of Educational Sciences and Teachers' Training, An Najah National University, Nablus, Palestine 